***This manuscript is currently in press at Personality Disorders: Theory, Research, and Treatment. (C) 2020, American Psychological Association. This paper is not the copy of record and may not exactly replicate the final, authoritative version of the article. Please do not copy or cite without authors' permission. The final article will be available, upon publication, via its DOI: $10.1037 /$ per0000403***

\title{
Examining the association between childhood cognitive ability and psychopathic traits at age 48
}

\author{
Nicholas Kavisha* \\ Henriette Bergstrømb \\ Chelsey Narveyc \\ Alex R. Piquerod \\ David P. Farringtone \\ Brian B. Boutwellf,g
}

a* Corresponding author. Department of Psychology and Philosophy, Sam Houston State University, Huntsville, TX USA; Email: nak012@shsu.edu

b Department of Social Sciences, University of Derby, Derby UK

c College of Criminal Justice, Sam Houston State University, Huntsville, TX

d Program in Criminology, The University of Texas at Dallas, Richardson, TX USA \& Department of Criminology, Monash University, Melbourne, VIC AUS

e Psychological Criminology, Institute of Criminology, Cambridge University, Cambridge UK

f Department of Legal Studies, School of Applied Sciences, The University of Mississippi Oxford, MS 38677

g John D. Bower School of Population Health, University of Mississippi Medical Center, Jackson, MS 39216

Acknowledgements: We are very grateful to the Home Office, the Department of Health, the Department of Education, the Rayne Foundation, the Barrow Cadbury Trust, and the Smith-Richardson Foundation for funding the Cambridge Study in Delinquent Development. 


\begin{abstract}
Despite early theorists suggesting that psychopathic traits are associated with higher intelligence, meta-analytic work has found that global psychopathy scores are actually negatively related to intelligence, albeit weakly. Furthermore, it was reported in the same meta-analytic work that the various dimensions of psychopathy were differentially related to intelligence. Importantly, virtually all of the research to date has relied on crosssectional associations. The current study examined whether intelligence scores (verbal comprehension, non-verbal IQ, and a global intelligence composite) at age 8 were associated with psychopathy scores at age 48 in a sample of white, urban males from London (analytical $n=292$ ). Results suggested a significant, but weak, inverse association between intelligence and the affective, lifestyle, and antisocial facets of psychopathy and a nonsignificant association with the interpersonal facet, as assessed by the Psychopathy Checklist: Screening Version. These findings contribute to the growing body of evidence suggesting that psychopathy, as conceptualized in most modern models, is either very weakly inversely related to, or simply not a correlate of intelligence.
\end{abstract}

Keywords: verbal intelligence; non-verbal intelligence; psychopathic traits; psychopathy; cognitive ability 
The past decades have been awash with research on psychopathy, with studies focusing on a variety of topics (e.g., Patrick, 2018). Receiving less attention, at least initially, was the association between psychopathy and intelligence. Early clinical observations (Cleckley, 1941/1982) suggested that psychopathic individuals typically posses "good intelligence". Intelligence was only one of 16 characteristics listed by Cleckley, however, and some contemporary researchers have questioned the representativeness of Cleckley's patients (e.g., Hare \& Neumann, 2008) and pointed out that his prototype does not appear to match the modern prototype of a psychopath (see Crego \& Widiger, 2016). Nevertheless, the "mythos" of the highly intelligent psychopath has been prominently featured in the lay public, with media portrayals of psychopathic “criminal masterminds" such as Patrick Bateman or Hannibal Lecter (DeLisi, Vaughn, Beaver, \& Wright, 2010).

To the contrary, early empirical tests suggested the "good intelligence" hypothesis did not hold up well for contemporary approaches to psychopathy, as global psychopathy scores were inversely correlated with indicators of intelligence (e.g., O'Kane, Fawcett, \& Blackburn, 1996). As researchers have increasingly recognized the multidimensional nature of psychopathy, studies have more recently examined the associations between factors or facets of psychopathy and intelligence and found evidence for differential associations between the traits (e.g., Vitacco, Neumann, \& Jackson, 2005; Vitacco, Neumann, \& Wodushek, 2008). Very recently, Sanchez de Ribera and colleagues (2019) meta-analyzed much of the literature on the topic including more than 100 effect sizes $(k$ $=6-12$, for facet level analyses). Their analyses found evidence for a weak, positive association between intelligence and the Interpersonal facet of psychopathy $(r=.14)$, but 
a weak, negative association between intelligence and the Affective facet $(r=-.16)$.

Associations with the Lifestyle and Antisocial facets were also negative, but not statistically significant.

Despite the growing amount of research on this topic, key questions remain. Virtually all of the research in this area has been cross-sectional, and it is unclear if intelligence early in life is even associated with psychopathy scores in late midadulthood. Personality traits are also not perfectly stable, and can shift across development owing to age and other factors (both environmental and genetic) (TuckerDrob \& Briley, 2019). Returning also to a theoretical vantage point, as Hare and Neumann (2008; p. 217) point out: the lingering "literal and uncritical acceptance [of Cleckley] by the research community has become problematical."1 This continues to shift with time of course, but remnants of it remain (in the clinical and lay-public as well), aspects of which involve a tendency to regard psychopathic individuals as possessing average to higher levels of intelligence. Thus, examining intelligence and psychopathy in a longitudinal sample (in addition to the cross-sectional work), seems a critical part of the endeavor to continuously update the "state of the art" of psychopathy research.

To further explore these issues, we analyze data drawn from a sample of males in the United Kingdom who have been followed since ages 8-10, and which include multiple indices of intelligence at age 8 and psychopathic traits at age 48 . We hypothesized that intelligence would be positively related to the Interpersonal facet of

1 We would like to thank the editor for providing this feedback and suggestion about the theoretical relevance of our paper, as well as alerting us to the quote that we reference from Hare and Neumann (2008). 
psychopathy and negatively related the Affective, Lifestyle, and Antisocial facets, generally in line with meta-analytic findings from cross-sectional research.2

\section{Methods}

\section{Design and sample}

The Cambridge Study in Delinquent Development (CSDD) is well known and has been described numerous times to date (Farrington, Piquero, \& Jennings, 2013). The original design included 411 boys from a white working-class area in London in the United Kingdom prospectively from the age of 8 to 56 (Farrington, Piquero, \& Jennings, 2013). The data collected included biological, psychological, and social factors (see Farrington \& Bergstrøm, 2018). Not all participants completed all age 48 measures which contain the psychopathy data - so the final analytical sample was 292 . Because all participants were Caucasian males and were the same age, we could not compare those with data to those without data on common demographic variables; however, those included in the analyses did not significantly differ from those excluded on childhood $\operatorname{SES}(\chi 2(3)=4.60, p=.204)$, whether or not they had been convicted of a crime $(\chi 2(1)=$ $.81, p=.367)$, or on childhood estimates of verbal $(t(395)=1.35, p=.177)$ and nonverbal $(t(409)=.06, p=.951)$ intelligence. Use of logistic regression with study variables as predictors of a "missingness" variable $(0=$ included; $1=$ excluded due to missing data $)$ also failed to provide evidence of significant differences between the two groups.

\section{Measures}

2 We also explored the possibility of curvilinear associations between IQ and psychopathy. Because these analyses were exploratory, we removed them to conserve space, but provide results at: https://osf.io/wvj6t/. 
IQ. Both verbal and non-verbal indicators or estimates of intelligence at age 8 were included as potential predictors in the current study.

Non-Verbal Intelligence (NVIQ). To estimate non-verbal intelligence, Raven's Progressive Matrices (RPM; Raven, 1938/1956) were administered in a group setting to the sample at age 8 (West, 1969). The RPM consists of five sets of 12 printed problems, without written directions. For each problem, the participant selects which of six to eight alternate options to complete a presented pattern or sequence. Scores on the RPM are strongly correlated with scores on other well-established intelligence tests such as the Wechsler Adult Intelligence Scales (WAIS; Wechsler, 1955; see McLaurin et al., 1973). Verbal Intelligence (VIQ). To estimate verbal intelligence at age 8 , the boys completed the Word Comprehension Test, a 50-item vocabulary test designed by the National Foundation for Educational Research for the National Survey of Health and Development (NSHD; Douglas \& Pigeon, 1964). In the NSHD, scores on the Word Comprehension Test loaded onto a single factor along with tests of reading comprehension, word reading, and non-verbal reasoning, and this general factor was strongly correlated with adult reading skills on the National Adult Reading Test (NART; Nelson \& Willison, 1991; see Richards et al., 2019). Importantly, the NART is strongly associated $(r \approx .5-.6)$ with scores on the WAIS (e.g., Dykiert \& Deary, 2013; Mathias et al., 2007).

Global intelligence (GIQ). A global intelligence composite score was created for each participant by taking the average of their scores on the verbal and non-verbal intelligence tests. 
Psychopathy. Psychopathy Checklist: Screening Version (Hart, Cox, \& Hare, 1995). The PCL:SV is a screening version of the Hare Psychopathy Checklist-Revised (Hare, 2003). The PCL:SV consists of 12 items that load onto 2 factors: Factor 1 (Interpersonal/Affective) and Factor 2 (Lifestyle/Antisocial), and 4 facets: facet 1 (Interpersonal), facet 2 (Affective), facet 3 (lifestyle), and facet 4 (antisocial). The score on the PCL:SV ranges from 0 to 24 , where the higher the score, the higher the individual is on psychopathic symptoms (Hart, Cox, \& Hare,1995). Prior research supports the use of the PCL:SV as an effective screening version of the Psychopathy Checklist-Revised (Hare, 2003; see Cooke, Michie, Hart, \& Hare, 1999). The PCL:SV was administered during the age 48 social interview.

Covariate. One potential covariate was included in the analyses. A socioeconomic disadvantage variable (SES) was included which consisted of 4 categories based on the father's occupation (according to the General Register's Office's Classification of Occupations, 1960) when the boy was aged 8 and 10. The highest category indicates greatest disadvantage. Other common covariates in this area of research include age, gender, and race, however, our sample consists only of same-age Caucasian males.

\section{Results}

Descriptive statistics for study variables are presented in Table 1.3 Of note, scores on the PCL:SV were generally low, but in line with other community samples (e.g.,

3 We initially included a measure of the Five Factor Model of personality, the Big Five Inventory (John et al., 1991), from which we also calculated a FFM psychopathy score. Associations between BFI scales and other study variables suggested poor performance of the measure. Given limitations in journal space, and more importantly in the interest of transparency, these results are available in a file at: https://osf.io/wvj6t/. 
Neumann \& Hare, 2008). Correlations between study variables are presented in Table 2. Briefly, The Raven's nonverbal-IQ scores and Verbal Comprehension scores (henceforth NVIQ and VIQ, respectively) were moderately strongly intercorrelated. Both intelligence indices along with the global intelligence composite (Global IQ) were significantly, negatively associated with PCL:SV total, factor, and three of the four facet scores. No indicator of intelligence was statistically associated with the Interpersonal facet.

Bivariate analyses were followed by estimation of linear regression models with each indicator of intelligence separately predicting psychopathy scores (Supplementary Tables 1 and 2). Socioeconomic disadvantage (SES) ratings were included as covariates in all models, and only associations with $p<.01$ were considered significant due to the large number of analyses. Because SES was not a significant predictor in any model, regression results were generally the same as the bivariate results and we have chosen to place the regression models in the supplementary material.

Nonverbal IQ, VIQ, and Global IQ scores emerged as consistently, negatively related to PCL:SV total and Factor 2 scores $(\beta$ 's $=-.17$ to -.26$)$, but only the Global IQ score was significantly negatively related to Factor 1 scores $(b=-.03, S E=.01, \beta=-.17$, $p=.003$; associations for NVIQ and VIQ scores and Factor 1 fell just beyond our significance threshold at $p=.011$ and .012 , respectively, but are also suggestive of a negative association between intelligence and Factor 1 scores). At the facet level, a negative association emerged between all measures of intelligence and the Affective and Antisocial facets of the PCL:SV $(\beta$ 's $=-.17$ to -.27). NVIQ and Global IQ, but not VIQ, were negatively related to the Lifestyle facet and no evidence was found for an association between any intelligence score and the Interpersonal facet. 


\section{Discussion}

Intelligence and psychopathy are important precursors to antisocial behavior over the life course. Yet, less is known concerning the extent to which intelligence and psychopathy correlate with one another across the life-course. Accordingly, we used data on a sample of UK males in order to examine the extent to which intelligence in childhood correlates with psychopathy in late middle adulthood. Our study provided consistent evidence of a weak inverse relationship between intelligence and scores on the total and factor variables, particularly Factor 2, of the PCL:SV. With respect to the relationships of intelligence to the facet scores, the results were a bit more complicated. All three measures of intelligence were negatively related to the affective and antisocial facets, and NVIQ and Global IQ were significantly inversely related to the lifestyle component (VIQ was also negatively associated, but not statistically significant).

Overall, a pattern emerged in our results suggesting that lower intelligence in childhood is weakly associated with higher levels of callous, impulsive, and antisocial traits, even 40 years later. This pattern is generally in accordance with cross-sectional meta-analytic findings that intelligence is negatively related to the affective facet and also inversely related to the lifestyle and antisocial facets, albeit not in a statistically significantly manner (Sanchez de Ribera et al., 2019). In contrast to the meta-analytic findings, we did not find any support for a positive association between intelligence and the interpersonal facet of psychopathy. And while some prior research has suggested that verbal intelligence in particular may be related to psychopathic traits (e.g., Salekin et al., 2004), examination of confidence intervals suggested that the associations typically did not vary across intelligence indices in our sample. Relatedly, Sanchez de Ribera and 
colleagues (2019) used meta-analytic structural equation modeling to assess the contributions of VIQ and performance IQ (somewhat analogous to NVIQ) and found that VIQ accounted for most of the variance in global psychopathy that could be explained by IQ; however, this was still only about $1 \%$ of the variance.

There are several advantages to our work, including the longitudinal data spanning childhood to late middle adulthood as well as the use of different types of intelligence measures. But some limitations must be noted. In particular, our indices for non-verbal and verbal cognitive ability were relatively brief measures that are meant to estimate verbal and non-verbal ability, rather than being comprehensive assessments of these constructs. Additionally, the generalizability of our sample is questionable given it consisted solely of same-age, white British males. Future research may benefit from replication using more diverse samples, more time points, more comprehensive measures of intelligence, and multi-method assessment of psychopathic traits. Furthermore, future research would benefit from the use of structural equation modeling techniques to account for the effects of measurement error, as we were not able to in the current study due to our modest sample size (for a discussion of sample size requirements for latent correlation stability, see Kretzschmar \& Gignac, 2019).

\section{Conclusion}

As noted in the introduction, current conceptualizations of psychopathy have drifted from Cleckley's descriptions of his unrepresentative sample of patients. The clearest result of the current study, in conjunction with previous meta-analytic work, is that "good intelligence" does not appear to be a feature of psychopathy. At most, lower levels of intelligence may be very weak indicators of risk for the affective and behavioral 
features of psychopathy, but the associations are small enough that clinical efforts to understand the etiology of, and intervene on, psychopathy and associated behavioral problems may be better spent examining alternative avenues, such as improving parenting and parental resources (in particular, the ability of parents to recognize early clinical signs and access affordable psychological services) and increasing self-control (see Piquero et al., 2016a; 2016b). 


\section{References}

Cleckley, H. (1941/1982). The Mask of Sanity. St. Louis, MO: Mosby.

Cooke, D. J., Michie, C., Hart, S. D., \& Hare, R. D. (1999). Evaluating the Screening Version of the Hare Psychopathy Checklist—Revised (PCL: SV): An item response theory analysis. Psychological Assessment, 11(1), 3-13.

DeLisi, M., Vaughn, M. G., Beaver, K. M., \& Wright, J. P. (2010). The Hannibal Lecter myth: Psychopathy and verbal intelligence in the MacArthur violence risk assessment study. Journal of Psychopathology and Behavioral Assessment, 32(2), 169-177.

Douglas, J. W. B. \& Pigeon, D. A. (1964). Tests used in the 1954 and 1957 surveys. In Douglas, J. W. B., (ed.). The home and the school. London: Macgibbon \& Key, p.129-132.

Dykiert, D., \& Deary, I. J. (2013). Retrospective validation of WTAR and NART scores as estimators of prior cognitive ability using the Lothian Birth Cohort 1936. Psychological Assessment, 25(4), 1361-1366.

Farrington, D.P. and Bergstrøm, H. (2018), "Family background and psychopathy”, in Patrick, C.J. (Ed.), Handbook of Psychopathy, 2nd ed., Guilford Publications, New York, NY, pp. 354-79.

Farrington, D. P., Piquero, A. R., \& Jennings, W. G. (2013). Offending from childhood to late middle age: Recent results from the Cambridge study in delinquent development. New York: Springer.

Hare, R. D. (2003). The Hare psychopathy checklist-revised: Manual. Toronto: MultiHealth Systems. 
Hare, R. D., \& Neumann, C. S. (2008). Psychopathy as a clinical and empirical construct. Annual Review of Clinical Psychology, 4, 217-246.

Hart, S. D., Cox, D. N., \& Hare, R. D. (1995). Hare psychopathy checklist: Screening version (PCL: SV). Toronto: Multi-Heath Systems.

Kaslow, F. W., Lipsitt, P. D., Buka, S. L., \& Lipsitt, L. P. (1990). Family law issues in family therapy practice: Early intelligence scores and subsequent delinquency: A Prospective study. American Journal of Family Therapy, 18(2), 197-208.

Major, J. T., Johnson, W., \& Deary, I. J. (2014). Linear and nonlinear associations between general intelligence and personality in Project TALENT. Journal of personality and social psychology, 106(4), 638-654.

Mathias, J. L., Bowden, S. C., \& BARRETT-WOODBRIDGE, M. I. K. E. L. E. (2007). Accuracy of the Wechsler Test of Adult Reading (WTAR) and National Adult Reading Test (NART) when estimating IQ in a healthy Australian sample. Australian Psychologist, 42(1), 49-56.

McLaurin, W. A., Jenkins, J. F., Farrar, W. E., \& Rumore, M. C. (1973). Correlations of IQs on verbal and nonverbal tests of intelligence. Psychological Reports, 33(3), $821-822$.

Nelson, H. E., \& Willison, J. (1991). National adult reading test (NART). Windsor: NferNelson.

Neumann, C. S., \& Hare, R. D. (2008). Psychopathic traits in a large community sample: links to violence, alcohol use, and intelligence. Journal of consulting and clinical psychology, 76(5), 893-899. 
O'Kane, A., Fawcett, D., \& Blackburn, R. (1996). Psychopathy and moral reasoning: Comparison of two classifications. Personality and Individual Differences, 20(4), $505-514$.

Patrick, C. J. (Ed.). (2018). Handbook of psychopathy (2nd ed.). New York, NY, US: The Guilford Press.

Piquero, A. R., Jennings, W. G., Diamond, B., Farrington, D. P., Tremblay, R. E., Welsh, B. C., \& Gonzalez, J. M. R. (2016a). A meta-analysis update on the effects of early family/parent training programs on antisocial behavior and delinquency. Journal of Experimental Criminology, 12(2), 229-248.

Piquero, A. R., Jennings, W. G., Farrington, D. P., Diamond, B., \& Gonzalez, J. M. R. (2016b). A meta-analysis update on the effectiveness of early self-control improvement programs to improve self-control and reduce delinquency. Journal of Experimental Criminology, 12(2), 249-264.

Rammstedt, B., Danner, D., \& Martin, S. (2016). The association between personality and cognitive ability: Going beyond simple effects. Journal of Research in Personality, 62, 39-44.

Raven, J. C. (1938/1956). Guide to Progressive Matrices (1938) (rev. ed.). London: H. K. Lewis.

Richards, M., James, S. N., Sizer, A., Sharma, N., Rawle, M., Davis, D. H., \& Kuh, D. (2019). Identifying the lifetime cognitive and socioeconomic antecedents of cognitive state: seven decades of follow-up in a British birth cohort study. $B M J$ open, 9(4), e024404. 
Salekin, R. T., Neumann, C. S., Leistico, A. M. R., \& Zalot, A. A. (2004). Psychopathy in youth and intelligence: An investigation of Cleckley's hypothesis. Journal of Clinical Child and Adolescent Psychology, 33(4), 731-742.

Salekin, R. T., Rogers, R., \& Sewell, K. W. (1996). A review and meta - analysis of the Psychopathy Checklist and Psychopathy Checklist - Revised: Predictive validity of dangerousness. Clinical Psychology: Science and Practice, 3(3), 203-215.

Sánchez de Ribera, O., Kavish, N., Katz, I. M., \& Boutwell, B. B. (2019). Untangling intelligence, psychopathy, antisocial personality disorder, and conduct problems: A meta-analytic review. European Journal of Personality, 33(5), 529-564.

Tucker-Drob, E. M., \& Briley, D. A., (2019). Theoretical concepts in the genetics of personality development. In McAdams, D. P., Shiner, R. L., \& Tackett, J. L. (Eds.) Handbook of Personality. Guilford Publications, New York, NY.

Vitacco, M. J., Neumann, C. S., \& Jackson, R. (2005). Development of a four-factor model of psychopathy: Associations with ethnicity, gender, violence, and intelligence. Journal of Consulting and Clinical Psychology, 73, 466-476.

Vitacco, M. J., Neumann, C. S., \& Wodushek, T. (2008). Differential relationships between the dimensions of psychopathy and intelligence: Replication with adult jail inmates. Criminal Justice and Behavior, 35(1), 48-55.

Wechsler, D. (1955). WAIS manual. New York: Psychological Corp.

West, D. J. (1969). Present Conduct and Future Delinquency. London: Heinemann. 
Table 1. Descriptive statistics of study variables.

\begin{tabular}{lcccc}
\hline & Mean & SD & Min & Max \\
\hline Global IQ & 98.46 & 10.83 & 75 & 128 \\
Nonverbal IQ & 102.30 & 13.81 & 75 & 126 \\
Verbal IQ & 94.61 & 11.47 & 70 & 130 \\
PCL:SV Total & 3.5 & 3.85 & 0 & 17 \\
PCL:SV F1 & 1.16 & 1.57 & 0 & 8 \\
PCL:SV F2 & 2.34 & 2.63 & 0 & 11 \\
PCL:SV Interpersonal & .50 & .83 & 0 & 4 \\
PCL:SV Affective & .65 & 1.04 & 0 & 5 \\
PCL:SV Lifestyle & .62 & 1.07 & 0 & 5 \\
PCL:SV Antisocial & 1.72 & 1.82 & 0 & 6 \\
\hline SES Category & Frequency & $\%$ & & \\
\hline I & 12 & 4.1 & & \\
II & 149 & 51 & & \\
III & 72 & 24.7 & & \\
IV & 59 & 20.2 & & \\
\hline
\end{tabular}

Note. Global IQ = average of Raven's IQ and Verbal Comprehension scores. PCL:SV = Psychopathy Checklist Screening Version. F1 = Affective factor. F2 = Antisocial Factor. 
Table 2. Correlation matrix for intelligence, psychopathy, and socioeconomic status variables.

\begin{tabular}{|c|c|c|c|c|c|c|c|c|c|c|c|}
\hline & 1 & 2 & 3 & 4 & 5 & 6 & 7 & 8 & 9 & 10 & 11 \\
\hline 1. GIQ & 1 & & & & & & & & & & \\
\hline 2. NVIQ & .88 & 1 & & & & & & & & & \\
\hline 3. VIQ & .83 & .46 & 1 & & & & & & & & \\
\hline 4. PCL:SV & -.24 & -.23 & -.18 & 1 & & & & & & & \\
\hline 5. F1 & -.16 & -.14 & -.14 & .86 & 1 & & & & & & \\
\hline 6. F2 & -.26 & -.26 & -.18 & .95 & .65 & 1 & & & & & \\
\hline 7. Interpersonal & -.07 & -.06 & -.05 & .65 & .80 & .47 & 1 & & & & \\
\hline 8. Affective & -.19 & -.16 & -.17 & .77 & .88 & .61 & .40 & 1 & & & \\
\hline 9. Lifestyle & -.19 & -.20 & -.13 & .80 & .55 & .84 & .38 & .54 & 1 & & \\
\hline 10. Antisocial & -.26 & -.26 & -.18 & .90 & .62 & .95 & .46 & .57 & .63 & 1 & \\
\hline 11. SES & .10 & .13 & .05 & .01 & .09 & -.03 & .07 & .08 & -.10 & .01 & 1 \\
\hline
\end{tabular}

average of Raven's IQ (NVIQ) and Verbal Comprehension (VIQ) scores. PCL:SV = Psychopathy Checklist Screening Version. F1 = Affective factor. F2 = Antisocial Factor. SES = SES category. 